\title{
Evolución de los niveles séricos de proteína C-reactiva y procalcitonina tras resección hepática
}

\author{
Elías Domínguez-Comesaña ${ }^{1}$, Santiago Domínguez-Fernández , Elías Domínguez-Fernández", \\ Rubén Domínguez-Fernández ${ }^{2}$ y Nazaret Quiroga-Veiga ${ }^{3}$
}

\section{Evolution of C-reactive protein and procalcitonin serum levels after hepatic resection}

\begin{abstract}
Aim: To evaluate the postoperative evolution of C-reactive protein and procalcitonin after hepatic resection. Materials and Method: Prospective observational study, including patients with different types of hepatic resection, without infectious or major postoperative complications. Procalcitonin and C-reactive protein serum levels were measured on the day prior to surgery and every day after surgery until the seventh postoperative day. Results: Forty-two patients were included. There was a significant correlation between procalcitonin levels at 24 hours after surgery and the overall length of surgery $(\mathrm{p}=$ 0.04). C-reactive protein was higher in non-lobar hepatectomies than in lobar hepatectomies 48 hours after surgery $(p=0.049)$. Procalcitonin was higher in major hepatectomies than in minor hepatectomies 24 hours after surgery $(\mathrm{p}=0.017)$. Procalcitonin levels were significantly lower in patients with laparoscopic approach in the first four postoperative days. Conclusion: Hepatic resection increases the serum levels of C-reactive protein and procalcitonin, but with less intensity if the approach is laparoscopic. C-reactive protein levels tend to be higher in less extensive hepatectomies and procalcitonin levels tend to be higher in more extensive resections.
\end{abstract}

Key words: procalcitonin; C-reactive protein; hepatectomy; postoperative; laparoscopy.

\section{Resumen}

Objetivo: Evaluar la evolución de los niveles séricos de proteína C-reactiva y procalcitonina tras resección hepática. Materiales y Método: Estudio observacional prospectivo, con pacientes con diferentes tipos de resección hepática, sin infección ni complicaciones mayores posoperatorias. Los niveles de proteína C-reactiva y procalcitonina se midieron el día anterior a la cirugía y diariamente, hasta el $7^{\circ}$ día, o hasta el alta, lo primero que ocurriera. Resultados: Se incluyeron 42 pacientes. Los niveles de procalcitonina, a las $24 \mathrm{~h}$, correlacionaban significativamente con la duración de la operación $(\mathrm{p}=0,04)$. A las $48 \mathrm{~h}$, los niveles de proteína C-reactiva fueron mayores en las resecciones hepáticas no lobares que en las lobares $(p=0,049)$. A las $24 \mathrm{~h}$, los niveles de procalcitonina aumentaron más en las hepatectomías mayores que en las menores $(p=0,017)$. Los niveles de procalcitonina fueron significativamente menores en los pacientes con abordaje laparoscópico en los 4 primeros días. Conclusión: La resección hepática produce un aumento de los niveles séricos de proteína C-reactiva y procalcitonina, pero con menor intensidad si el abordaje es laparoscópico. Los niveles séricos de proteína C-reactiva tienden a ser mayores en las hepatectomías menos extensas, mientras que los de procalcitonina tienden a ser mayores en las más extensas.

Palabras clave: procalcitonina; proteína C-reactiva; hepatectomía; posoperatorio; laparoscopia.

\section{Introducción}

La procalcitonina (PCT) y la proteína C-reactiva (PCR) son marcadores inflamatorios, cuya producción aumenta después de diferentes tipos de cirugía $^{1,2}$. Ambos se han utilizado para excluir complicaciones inflamatorias, tales como abscesos intraabdominales y dehiscencias de suturas intestinales, particularmente en pacientes con cirugía colorrectal ${ }^{3}$. Sin embargo, no hay artículos focalizados en la utilidad de estos marcadores para excluir complicaciones después de una resección hepática. Dado que, en el contexto de la reacción inflamatoria, tanto la PCR como la PCT se producen principal-
'Servicio de Cirugía. 2Servicio de Urgencias. 3ervicio de Oncología. Complejo Hospitalario de Pontevedra, España.

Recibido 2020-05-20 y aceptado 2020-06-13

Correspondencia a: Dr. Elías DomínguezComesaña eliasdomcom@gmail.com 


\section{ARTíCULO ORIGINAL}

mente en el hígado ${ }^{4}$, la resección hepática podría afectar a su producción en el posoperatorio. Por esta razón, llevamos a cabo este estudio, con el objetivo de conocer cuál es la evolución de estos marcadores tras resección hepática, como paso previo a un estudio para investigar su utilidad en el diagnóstico de complicaciones posoperatorias después de cirugía hepática.

\section{Materiales y Método}

Se llevó a cabo un estudio observacional prospectivo en el que se incluyeron pacientes consecutivos a quienes se les hizo una resección hepática electiva, con abordaje laparoscópico o laparotómico, entre el $1^{\circ}$ de octubre de 2016 y el 18 de mayo de 2018 . Los criterios de exclusión fueron: edad inferior a 18 años, cirugía urgente o paliativa, valores preoperatorios de PCT mayores de $0,5 \mathrm{ng} / \mathrm{ml}$, infección activa antes de la cirugía, fallo hepático posoperatorio, infección posoperatoria y otras complicaciones posoperatorias grado III o mayor de la clasificación de Clavien ${ }^{5}$. Todos los pacientes recibieron profilaxis antimicrobiana preoperatoria con una combinación de 2 g de amoxicilina y $200 \mathrm{mg}$ de ácido clavulánico, administrados por vía endovenosa en la hora que precedía a la cirugía. En caso de alergia a betalactámicos, se utilizó el ciprofloxacino a dosis de $400 \mathrm{mg}$ por vía endovenosa. La hepatectomía mayor se definió como la resección de tres o más segmentos; cualquier otra resección fue definida como menor. La hepatectomía lobar se definió como la resección del lóbulo derecho o del lóbulo izquierdo; cualquier otra resección se definió como no lobar.

Los niveles séricos de PCR y PCT se midieron el día previo a la cirugía (D0) y diariamente después de la misma, hasta el séptimo día de posoperatorio (D1 a D7) o hasta el alta, lo que ocurriese primero. La PCR fue determinada por un método inmunotur-

Tabla 1. Tipo de resección hepática $(n=42)$

\begin{tabular}{|lcc|}
\hline & $\begin{array}{c}\text { Laparoscopia } \\
(\mathbf{n}=\mathbf{2 9})\end{array}$ & $\begin{array}{c}\text { Laparotomía } \\
(\mathbf{n}=\mathbf{1 3})\end{array}$ \\
\hline Hepatectomía derecha & 5 & 3 \\
Hepatectomía izquierda & 2 & 2 \\
Seccionectomía lateral izquierda & 8 & 0 \\
1-2 segmentos & 4 & 2 \\
3 o más segmentos & 1 & 1 \\
Tumorectomía & 9 & 5 \\
\hline
\end{tabular}

bidométrico, utilizando un analizador automático Beckman Coulter Au 5420 (IZASA). La PCT fue determinada por medio de un inmunoensayo de electroquimioluminiscencia. Todos los pacientes firmaron un consentimiento informado y el estudio fue aprobado por el comité de ética de Galicia. El análisis estadístico se llevó a cabo utilizando el SPSS v 20.0 para Mac (Statistical Package for Social Sciences Inc., Chicago, Illinois, USA). La normalidad y homogeneidad de las variables cuantitativas se evaluó mediante el test de Kolmogorov-Smirnov y el test de Bartlett-Box, respectivamente. Las variables cuantitativas se expresaron como medias aritméticas \pm SD o como medianas con rango intercuartílico (Q1-Q3), según fuera apropiado. Para comparar variables cuantitativas entre grupos se utilizó el test de Mann-Whitney o el test $t$ de Student, según fuera apropiado. Para comparar variables categóricas entre grupos se utilizó el test exacto de Fisher o el test $\chi^{2}$, según fuera apropiado. La correlación entre la duración de la cirugía y los valores de PCR y PCT se valoró mediante el coeficiente de correlación de Spearman. La evolución de los valores de PCR y PCT a lo largo del tiempo se evaluó mediante el test de Wilcoxon. Se consideró que había significación estadística para valores de $\mathrm{p}$ inferiores a 0,05 .

\section{Resultados}

En el periodo de tiempo objeto del estudio se operaron 53 pacientes: 3 fueron excluidos por infección posoperatoria y 8 por complicaciones clasificadas como Clavien III o mayor. Los otros 42 pacientes fueron incluidos en el estudio. Veintitrés eran varones $(54,8 \%)$ y 19 mujeres $(45,2 \%)$. La edad media de los pacientes fue de $62,1 \pm 12$ años. Las indicaciones para la resección hepática fueron: metástasis (33 pacientes, 78,5\%), tumores malignos primarios ( 7 pacientes, $16,7 \%$ ) y tumores benignos ( 2 pacientes, 4,8\%). En 14 pacientes $(33,3 \%$ ) se hizo una hepatectomía mayor ( 8 hepatectomías derechas, 4 hepatectomías izquierdas y dos segmentectomías múltiples). En 12 pacientes (28,6\%) se hizo una hepatectomía lobar. En 29 pacientes (69\%) se utilizó un abordaje laparoscópico completo, con cuatro conversiones a laparotomía (13,8\%). En la Tabla 1 se muestran los tipos de resección hepática. La maniobra de Pringle se utilizó en 5 pacientes, con una duración de 14 a 40 min. La duración media de la cirugía fue de 228,7 $\pm 73 \mathrm{~min}$. La pérdida hemática media fue de 146,4 $\pm 118 \mathrm{ml}$. En la Tabla 2 se muestran las características de los pacientes, en función del tipo de resección hepática. Tanto la PCR como 
Tabla 2. Características clínicas y operatorias de los pacientes en función del tipo de resección

\begin{tabular}{|c|c|c|c|c|c|c|}
\hline Variable & $\begin{array}{c}\text { Laparoscopia } \\
n=29\end{array}$ & $\begin{array}{l}\text { Laparotomía } \\
\qquad n=13\end{array}$ & $\mathbf{p}$ & $\begin{array}{l}\text { Mayor } \\
n=14\end{array}$ & $\begin{array}{l}\text { Menor } \\
\mathbf{n}=\mathbf{2 8}\end{array}$ & $\mathbf{p}$ \\
\hline Edad, media \pm DE & $62,8 \pm 12$ & $61,7 \pm 12$ & 0,976 & $63,5 \pm 12$ & $61,5 \pm 12$ & 0,945 \\
\hline $\mathrm{IMC}$, media $\pm \mathrm{DE}$ & $27,8 \pm$ & $27,2 \pm$ & 0,459 & $27,1 \pm$ & $27,7 \pm$ & 0,436 \\
\hline ASA, I-II/III-IV & $12 / 17$ & $5 / 8$ & 0,112 & $6 / 8$ & $11 / 17$ & 0,145 \\
\hline Quimioterapia previa, sí/no & $8 / 21$ & $4 / 9$ & 0,158 & $9 / 5$ & $3 / 25$ & 0,01 \\
\hline Duración media de la cirugía \pm DE (min) & $217 \pm 65$ & $241 \pm 76$ & 0,02 & $305 \pm$ & $185 \pm$ & 0,01 \\
\hline Pérdida hemática media $\pm \mathrm{DE}(\mathrm{ml})$ & $129 \pm 115$ & $170 \pm 125$ & 0,04 & $250 \pm 130$ & $150 \pm 99$ & 0,03 \\
\hline Pringle, sí/no & $4 / 25$ & $1 / 12$ & 0,325 & $1 / 13$ & $4 / 24$ & 0,268 \\
\hline
\end{tabular}

DE: desviación estándar. V: varón. M: mujer. IMC: índice de masa corporal. ASA: Clasificación de la Asociación Americana de Anestesiólogos. NP: no procede.

la PCT aumentaron significativamente en todos los pacientes después de la cirugía. Ambas moléculas alcanzaron su pico a las $48 \mathrm{~h}$ de la cirugía, con medianas de 13,7 mg/dL, para la PCR (Tabla 3, Figura 1) y $0,7 \mathrm{ng} / \mathrm{mL}$, para la PCT (Tabla 4 , Figura 2). Posteriormente, los niveles de ambos marcadores disminuyeron progresivamente, pero no retornaron a los valores preoperatorios en el periodo de tiempo estudiado. La duración de la cirugía no tuvo impacto en los niveles de PCR, sin embargo, hubo una correlación significativa entre los valores de PCT a las $24 \mathrm{~h}$ de la cirugía y la duración de la misma $(p=0,04, r=0,335)$. Los niveles séricos de PCR tendían a ser mayores en los pacientes con hepatec- tomía menor que en los pacientes con hepatectomía mayor, pero las diferencias no fueron significativas. Por el contrario, los valores de PCT tendían a ser mayores en los pacientes con hepatectomía mayor, pero las diferencias sólo fueron significativas a las $24 \mathrm{~h}$ de la cirugía (Tabla 5). Los niveles de PCR tendían a ser mayores en los pacientes con hepatectomía no lobar comparados con los pacientes con hepatectomía lobar, pero las diferencias sólo fueron significativas a las $48 \mathrm{~h}$ de la cirugía. Sin embargo, los valores de PCT fueron mayores en los pacientes con hepatectomía lobar (Tabla 5). Los valores de PCR no fueron significativamente diferentes según que el abordaje fuera laparoscópico o laparotómico.

Tabla 3. Valores de proteína C-reactiva (PCR), expresados en mg/dL

\begin{tabular}{|lcccccccc|}
\hline & $\begin{array}{c}\text { PCR } \\
\text { D0 }\end{array}$ & $\begin{array}{c}\text { PCR } \\
\text { D1 }\end{array}$ & $\begin{array}{c}\text { PCR } \\
\text { D2 }\end{array}$ & $\begin{array}{c}\text { PCR } \\
\text { D3 }\end{array}$ & $\begin{array}{c}\text { PCR } \\
\text { D4 }\end{array}$ & $\begin{array}{c}\text { PCR } \\
\text { D5 }\end{array}$ & $\begin{array}{c}\text { PCR } \\
\text { D6 }\end{array}$ & $\begin{array}{c}\text { PCR } \\
\text { D7 }\end{array}$ \\
N & 42 & 42 & 42 & 41 & 32 & 21 & 14 & 8 \\
Mediana & 0,3 & 7,9 & 13,7 & 12,9 & 10,5 & 7,5 & 5,9 & 5,9 \\
Mínimo & 0,1 & 0,1 & 2 & 2 & 1,7 & 1,9 & 1,5 & 2,6 \\
Máximo & 2 & 16,8 & 31,2 & 31,1 & 26 & 20,2 & 18 & 10,3 \\
Percentil 25 & 0,18 & 5,93 & 9,65 & 9,75 & 6,95 & 5,5 & 4,8 & 4,55 \\
Percentil 75 & 0,73 & 8,95 & 17,73 & 18,85 & 15,78 & 9,95 & 9,68 & 9,4 \\
\hline
\end{tabular}




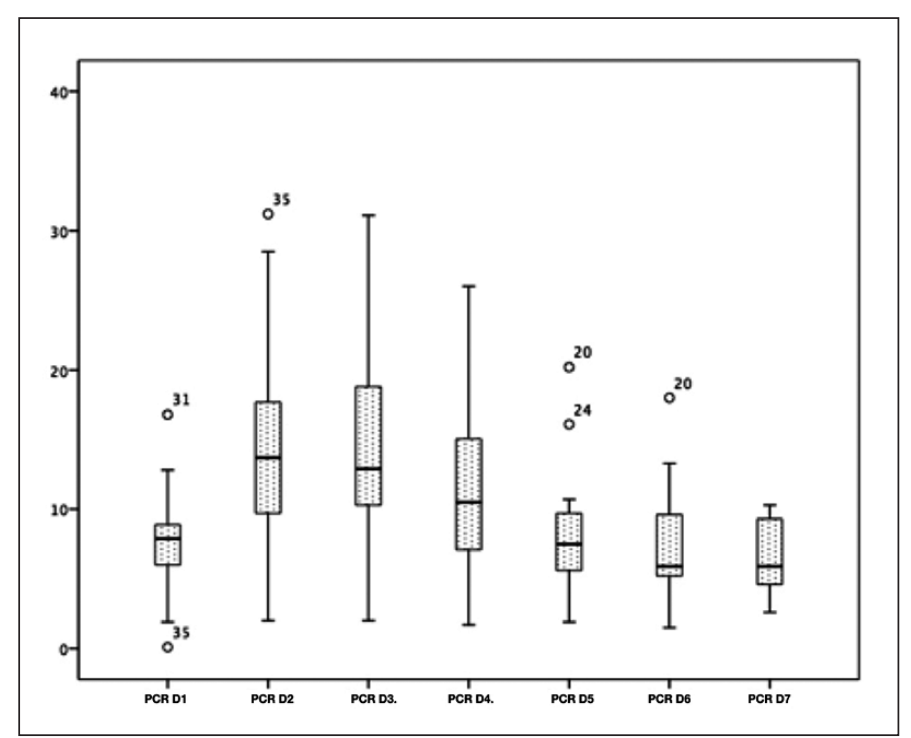

Figura 1. Diagrama de cajas para los valores de proteína C-reactiva $(P C R)$, en $\mathrm{mg} / \mathrm{dL}$. Las cajas muestran los percentiles 25,50 y 75 y los valores mínimos y máximos. El símbolo o representa los valores extremos.

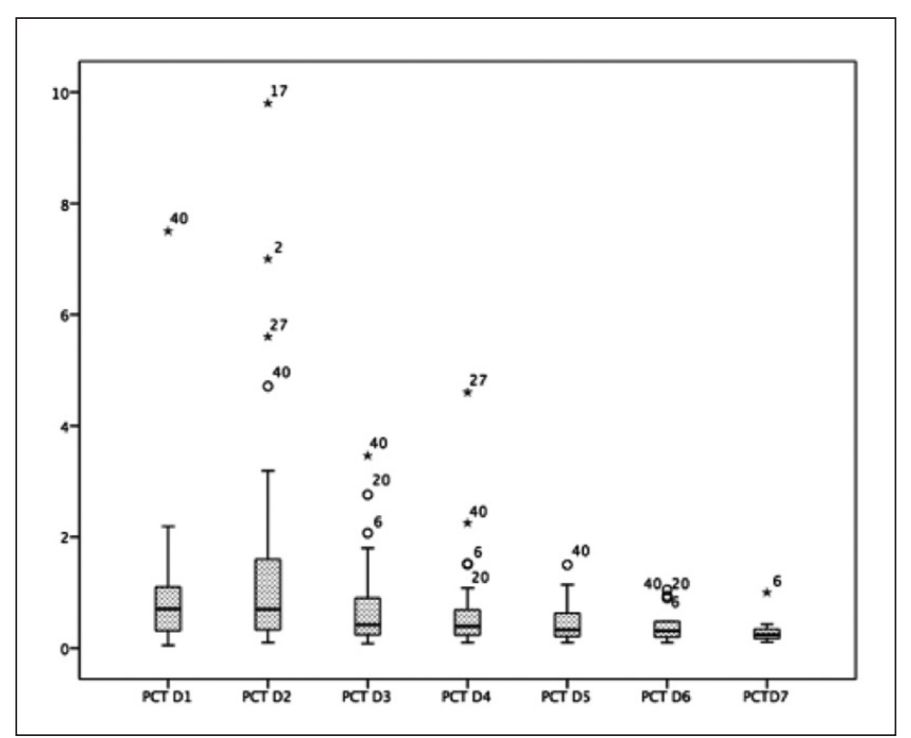

Figura 2. Diagrama de cajas para los valores de procalcitonina (PCT), en $\mathrm{ng} / \mathrm{mL}$. Las cajas muestran los percentiles 25,50 y 75 y los valores mínimos y máximos. Los símbolos $0 \star$ representan los valores extremos.

Tabla 4. Valores de procalcitonina (PCT), expresados en $\mathrm{ng} / \mathrm{ml}$

\begin{tabular}{|lcccccccc|}
\hline & $\begin{array}{c}\text { PCT } \\
\text { D0 }\end{array}$ & $\begin{array}{c}\text { PCT } \\
\text { D1 }\end{array}$ & $\begin{array}{c}\text { PCT } \\
\text { D2 }\end{array}$ & $\begin{array}{c}\text { PCT } \\
\text { D3 }\end{array}$ & $\begin{array}{c}\text { PCT } \\
\text { D4 }\end{array}$ & $\begin{array}{c}\text { PCT } \\
\text { D5 }\end{array}$ & $\begin{array}{c}\text { PCT } \\
\text { D6 }\end{array}$ & $\begin{array}{c}\text { PCT } \\
\text { D7 }\end{array}$ \\
N & 42 & 42 & 42 & 41 & 32 & 21 & 14 & 8 \\
Mediana & 0,05 & 0,71 & 0,7 & 0,42 & 0,395 & 0,33 & 0,31 & 0,24 \\
Mínimo & 0,02 & 0,05 & 0,1 & 0,08 & 0,1 & 0,1 & 0,1 & 0,11 \\
Máximo & 0,19 & 7,5 & 9,8 & 3,46 & 4,6 & 1,5 & 1,05 & 1 \\
Percentil 25 & 0,04 & 0,307 & 0,325 & 0,22 & 0,227 & 0,205 & 0,187 & 0,162 \\
Percentil 75 & 0,06 & 1,12 & 1,61 & 0,93 & 0,735 & 0,665 & 0,585 & 0,385 \\
\hline
\end{tabular}

Sin embargo, los valores de PCT fueron significativamente mayores en los pacientes con abordaje por laparotomía a las 24,48 , 72 y 96 h después de la cirugía (Tabla 5, Figura 3).

\section{Discusión}

Tanto la PCR como la PCT son moléculas cuya producción se incrementa en el contexto de la respuesta inflamatoria que se inicia tras la agresión a las células del organismo. La PCR es producida principalmente en el hígado en respuesta a la IL- $6^{4}$, mientras que la PCT es producida por macrófagos ${ }^{6}$ y células neuroendocrinas de diversos órganos, especialmente hígado y pulmón ${ }^{7,8}$, en respuesta a endotoxinas bacterianas y algunas citoquinas, principalmente, IL-1, IL-6 and TNF- $\alpha^{9}$. Además, ambas moléculas son marcadores de inflamación (aunque la PCT es más específica de infección ${ }^{10} \mathrm{y}$, por este motivo, se han utilizado como herramienta de evaluación posoperatoria, específicamente para el diagnóstico de complicaciones posoperatorias, sobre todo, en pacientes con cirugía del colon y del recto ${ }^{3,11,12}$. Ambos marcadores tienen un valor predictivo negativo muy alto, alrededor del $95 \%$ o más, para las complicaciones inflamatorias e infecciosas, por ello, pueden ser especialmente útiles para facilitar el alta precoz segura ${ }^{3,13}$. Estos marcadores también podrían ser utilizados para la evaluación posoperatoria de los pacientes tras resección hepática. Para facilitar la interpretación de los resultados es conveniente conocer cuál es la evolución natural de estos marcadores en este tipo de pacientes. Esto es especial- 
Tabla 5. Concentraciones séricas de proteína C-reactiva $(\mathrm{mg} / \mathrm{dL})$ y procalcitonina $(\mathrm{ng} / \mathrm{mL})$, según el tipo de resección hepática

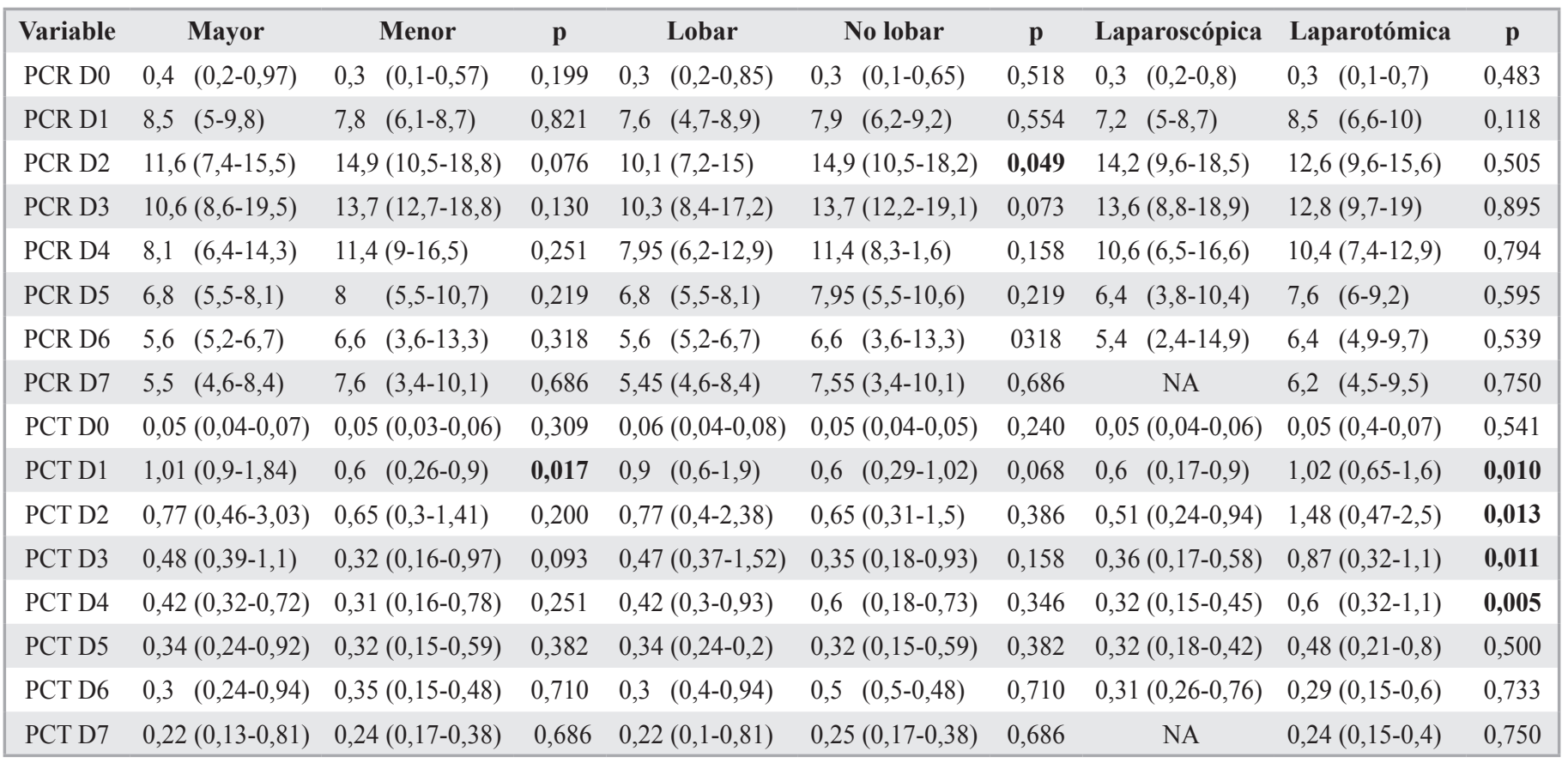

Los valores se expresan como medianas y percentiles 25 y 75 (entre paréntesis). PCR: proteína C-reactiva PCT: procalcitonina NA: No aplicable.

mente importante si tenemos en consideración que el hígado juega un papel crucial en la producción de ambas moléculas ${ }^{4,7,8}$ y que, por ello, la extensión de la resección hepática podría afectar a las concentraciones posoperatorias de las mismas. Hasta ahora, sólo se han publicado cuatro artículos en los que se aborda este tema. Uno de ellos incluye 138 pacientes y analiza sólo la PCR en los días 1, 3 y 7 de posoperatorio ${ }^{14}$; un segundo estudio incluye 40 pacientes y analiza los valores de estos marcadores en los primeros 6 días de posoperatorio ${ }^{15} \mathrm{y}$, finalmente, otros dos estudios incluyen 28 pacientes cada uno y sólo analizan un periodo de 3 días $^{16}$ y $24 \mathrm{~h}^{17}$, respectivamente. En ninguno de estos estudios se analizó la concentración sérica de estas moléculas en función de si el abordaje era laparoscópico o por laparotomía. El número de pacientes incluido en nuestro estudio es bajo, pero todos tuvieron un curso posoperatorio sin complicaciones infecciosas o graves, que podrían afectar a la producción de PCR y PCT, como se ha visto en otros tipos de cirugía ${ }^{3,12}$ $\mathrm{y}$, además, ninguno de los pacientes incluido en el estudio tuvo fallo hepático posoperatorio, que podría influir en la síntesis de PCR ${ }^{14}$. Por ello, se puede considerar que en los pacientes incluidos en el estudio la producción de PCR y PCT está directamente

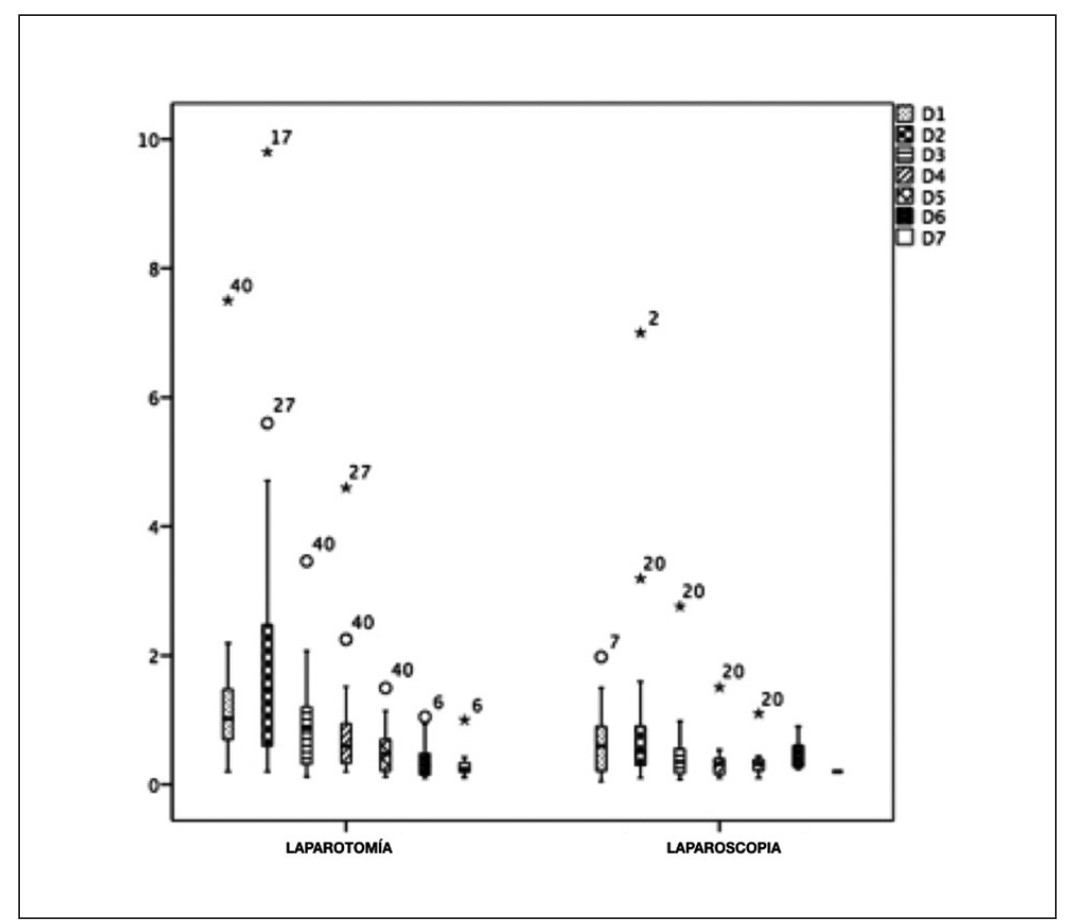

Figura 3. Diagrama de cajas para los valores de procalcitonina $(P C T)$, en $\mathrm{ng} / \mathrm{mL}$, en pacientes con abordaje laparoscópico y laparotómico. Las cajas muestran los percentiles 25, 50 y 75 y los valores mínimos y máximos. Los símbolos $0 \star$ representan los valores extremos. 
relacionada con la intervención quirúrgica, sin la interferencia de las complicaciones posoperatorias. En nuestro estudio se observó que tanto la PCR como la PCT se elevan en todos los pacientes tras la resección hepática, independientemente del tipo de resección realizada, en consonancia con los datos publicados por otros autores ${ }^{14-17}$. La máxima concentración se alcanza a las 48 h de la cirugía, tanto para la PCR como para la PCT, con una mediana de $13,7 \mathrm{mg} / \mathrm{dl}$ y $0,7 \mathrm{ng} / \mathrm{ml}$, respectivamente, y después se produce un progresivo descenso, sin que lleguen a restablecerse los valores preoperatorios durante el periodo de tiempo estudiado. Schwarz y cols. ${ }^{15}$, encontraron, en un estudio con 40 pacientes, que la PCR alcanzaba el pico de concentración algo más tarde, en el tercer día de posoperatorio, con valores entre 7 y 9,5 mg/dL, dependiendo de si la resección se hacía con disector ultrasónico o con stapler. Rahman y cols. ${ }^{14}$ también encontraron que la PCR alcanzaba su pico en el tercer día de posoperatorio, pero sólo analizaron los valores en los días 1, 3 y 7 de posoperatorio. Por otra parte, Marton y cols. ${ }^{16}$, encontraron que la PCT alcanzaba su máximo valor a las 24 h de la cirugía, antes que lo observado en nuestro estudio, pero hay que tener en cuenta que los valores correspondientes a las 24 y $48 \mathrm{~h}$ fueron muy similares. A la luz de estos resultados, parece que la máxima concentración de PCR y PCT se alcanza entre las 48 y las $72 \mathrm{~h}$ de posoperatorio. Para otros tipos de cirugía también se ha visto que las máximas concentraciones se alcanzan a las $24-48 \mathrm{~h}$ para la PCT, y a las 48-72 h para la $\mathrm{PCR}^{3,12,18}$. Según lo observado en nuestro estudio, la extensión de la resección hepática no parece tener demasiada influencia en la producción de PCR y PCT, aunque los niveles de PCR tienden a ser mayores en las hepatectomías menos extensas. Este hallazgo también fue encontrado por Rahman y cols. ${ }^{14}$ en el primer y tercer día de posoperatorio. A partir de los resultados de este estudio, no se puede deducir cuál es la explicación de que esto ocurra así, sin embargo, teniendo en cuenta que la PCR se sintetiza fundamentalmente en el hígado, una de las razones podría ser que, en las hepatectomías menores, el remanente hepático es mayor y, por lo tanto, con mayor capacidad para sintetizar esta molécula. Otra razón podría ser que las hepatectomías no lobares y menores suelen ser menos anatómicas y, por lo tanto, con mayor posibilidad de que haya más tejido mal vascularizado. Por el contrario, los niveles de PCT tienden a ser mayores en las resecciones más extensas y esto podría estar en relación, en primer lugar, con el hecho de que la PCT se produce de manera importante en localizaciones extrahepáticas y, en segundo lugar, porque hay una correlación positiva entre la duración de la cirugía y los niveles de PCT, sobre todo a las $24 \mathrm{~h}$ de la misma. En un estudio llevado a cabo por Schwarz y cols. ${ }^{15}$, al contrario de lo que ocurrió en el nuestro, también se observó que la duración de la cirugía se correlacionaba con la producción de PCR. Por último, en nuestro estudio pudimos observar que el abordaje laparoscópico reduce significativamente la producción de PCT, pero no la de PCR, al contrario de lo que ocurre en la cirugía colorrectal, en la que se ha visto que el abordaje laparoscópico también reduce significativamente la producción de $\mathrm{PCR}^{19}$.

La principal limitación de nuestro estudio es el bajo número de pacientes incluidos, por lo que los resultados deben ser interpretados con cautela, particularmente al considerar los diferentes tipos de resección hepática. Sin embargo, los resultados obtenidos en este estudio pueden ser útiles al plantear otros trabajos en los que se investigue la utilidad de la PCR y de la PCT para valorar la existencia de complicaciones posoperatorias, en función del tipo de resección hepática realizada.

\section{Conclusión}

La resección hepática induce el aumento de los niveles séricos de PCR y PCT, pero con menor intensidad si el abordaje es laparoscópico; la extensión de la resección hepática no parece tener una gran influencia en la producción de ambas moléculas, si bien los niveles de PCR tienden a ser mayores en las resecciones hepáticas menos extensas, mientras que los niveles de PCT tienden a ser mayores en las resecciones más extensas.

\section{Responsabilidades éticas}

Protección de personas y animales. Los autores declaran que para esta investigación no se han realizado experimentos en seres humanos ni en animales.

Confidencialidad de los datos. Los autores declaran que en este artículo no aparecen datos de pacientes.

Conflictos de interés: no hay. 


\section{Bibliografía}

1. Gans SL, Atema JJ, Van Dieren S, Koerkamp BG, Boermeester MA. Diagnostic value of C-reactive protein to rule out infectious complications after major abdominal surgery: a systematic review and meta-analysis. Int J Colorectal Dis. 2015;30:861-73. https://doi. org/10.1007/s00384-015-2205-y.

2. Mokart D, Merlin M, Sannini A, Brun JP, Delpero JR, Houvenaeghel G, et al. Procalcitonin, interleukin 6 and systemic inflammatory reponse syndrome (SIRS): early markers of postoperative sepsis after major surgery. Br J Anaesth. 2005;94:76773. https://doi.org/10.1093/bja/aei143.

3. Domínguez-Comesaña E, EstévezFernández SM, López-Gómez V, BallinasMiranda J, Domínguez-Fernández R. Procalcitonin and $\mathrm{C}$-reactive protein as early markers of postoperative intraabdominal infection in patients operated on colorectal cancer. Int J Colorectal Dis. 2017;32:1771-4. https://doi.org/10.1007/ s00384-017-2902-9.

4. Mackiewicz A, Speroff T, Ganapathi MK, Kushner I. Effects of cytokine combinations on acute phase protein production in two human hepatoma cell lines. J Immunol. 1991;146:3032-7.

5. Dindo D, Demartines N, Clavien PA. Classification of surgical complications. A new proposal with evaluation in a cohort of 6336 patients and results of a survey. Ann Surg. 2004;240:205-13. https://doi. org/10.1097/01.sla.0000133083.54934.ae

6. Oberhoffer M, Vogelsang H, Jäger L, Reinhart K. Katacalcin and calcitonin immunoreactivity in different types of leukocytes indicate intracellular procalcitonin content. J Crit Care. 1999;14:29-33. https://doi.org/10.1016/ s0883-9441(99)90005-9.
7. Becker KL, O’Neill WJ, Snider RH, Nylen ES, Jeng J, Silva OL, et al. Hypercalcitonemia in inhalation burn injury: A response of the pulmonary neuroendocrine cell? Anat Rec. 1993;236:136-8. https://doi.org/10.1002/ ar.1092360118.

8. Assicot M, Gendrel D, Carsin H, Raymond J, Guilbaud J, Bohuon C. High serum procalcitonin concentration in patients with sepsis and infection. Lancet 1993;341:515-8. https://doi. org/10.1016/0140-6736(93)90277-n.

9. Dandona P, Nix D, Wilson MF, Aljada A, Love J, Assicot M, et al. Procalcitonin increase after endotoxin injection in normal subjects. J Clin Endocrinol Metab. 1994;79:1605-8. https://doi.org/10.1210/ jcem.79.6.7989463.

10. Simon L, Gauvin F, Amre DK, SaintLouis P, Lacroix J. Serum procalcitonin and C-reactive protein levels as markers of bacterial infection: a systematic review and meta-analysis. Clin Infect Dis. 2004;39:206-17. https://doi. org/10.1086/421997.

11. Gans SL, Atema JJ, Van Dieren S, Koerkamp BG, Boermeester MA. Diagnostic value of C-reactive protein to rule out infectious complications after major abdominal surgery: a systematic review and meta-analysis. Int J Colorectal Dis. 2015;30:861-73. https://doi. org/10.1007/s00384-015-2205-y.

12. Cousin F, Ortega-Deballon P, Bourredjem A, Doussot A, Giacaglia V, Fournel I. Diagnostic accuracy of procalcitonin and C-reactive protein for the early diagnosis of intra-abdominal infection after elective colorectal surgery. Ann Surg. 2016;264:52-256. https://doi.org/10.1097/ SLA.0000000000001545.

13. Giaccaglia V, Salvi PF, Antonelli MS, Nigri G, Pirozzi F, Casagranda B, et al.
Procalcitonin reveals early dehiscence in colorectal surgery. The PREDICS study. Ann Surg. 2016;263:967-72. https://doi.org/10.1097/ SLA.0000000000001365.

14. Rahman SH, Evans J, Toogood GJ, Lodge PA, Prasad KR. Prognostic utility of postoperative C-reactive protein for posthepatectomy liver failure. Arch Surg. 2008;143:247-53. https://doi.org/10.1001/ archsurg.2007.75

15. Schwarz C, Fitschek F, Bar-Or B, Klaus DA, Tudor B, Fleischmann E, et al. Inflammatory response and oxidative stress during liver resection. PLoS One. 2017. https://doi.org/10.1371/journal. pone. 0185685 .

16. Márton S, Garai J, Molnár V, Juhász V, Bogá L, Köszegi T, et al. Kinetics of inflammatory markers following cancerrelated bowel and liver resection. Ups J Med Sci. 2011;116:124-8. https://doi.org/1 0.3109/03009734.2010.519446.

17. Kretzschmar M, Küger A, Schirrmeister W. Procalcitonin following elective partial liver resection-origin from the liver? Acta Anaesthesiol Scand. 2001;45:11627. https://doi.org/10.1034/j.13996576.2001.450918.x.

18. García-Granero A, Frasson M, FlorLorente B, Blanco F, Puga R, Carratalá $\mathrm{A}$, et al. Procalcitonin and C-reactive protein as early predictors of anastomotic leak in colorectal surgery: a prospective observational study. Dis Colon Rectum. 2013;56:475-83. https://doi.org/10.1097/ DCR.0b013e31826ce825.

19. Facy O, Paquette B, Orry D, Santucci N, Rat P, Rat P, et al. Inflammatory markers as early predictors of infection after colorectal surgery: the same cut-off values in laparoscopy and laparotomy? Int J Colorectal Dis. 2017;32:857-63. https:// doi.org/10.1007/s00384-017-2805-9. 